\title{
Enhanced quantitative urine culture technique, a slight modification, in detecting under-diagnosed pediatric urinary tract infection
}

\author{
Januka Thapaliya ${ }^{1 \dagger}$, Priyatam Khadka ${ }^{1{ }^{*}+}\left(\mathbb{0}\right.$, Shovana Thapa ${ }^{2}$ and Chenu Gongal ${ }^{1}$
}

\begin{abstract}
Objectives: The pediatric urinary tract infection (UTI) often remains under-diagnosed or neglected owing to non-specific clinical presentations, patients failing to describe the actual situation and of clinical practice in diagnosis. The study was aimed to determine the etiologies of UTI in children with enhanced quantitative urine culture (EQUC) technique.

Results: Of enrolled 570 pediatric urine samples, the significant growth positivity was higher in EQUC 92 (16.15\%) compared to standard urine culture (SUC) 73 (12.80\%) technique. 20.6\% of the significant isolates as detected with EQUC were missed on the SUC technique. The age group, in range 1-4 years, was more prone to the infection, where E. coli was the commonest pathogen. EQUC detected, probably all isolates, contributing UTI i.e. multidrug-resistant (MDR), extensive drug-resistant (XDR), and extended-spectrum $\beta$-lactamase (ESBL) producers, as some of them skipped on the SUC technique. Of total organisms isolated from EQUC, 46\% were ESBL producer, 56.5\% were MDR, and $1.4 \%$ were XDR. However, 40.5\% ESBL, 44\% MDR but no XDR detected on SUC. Hence a simple modification on conventional culture protocol could be a crucial modification for the detection of etiologies, contributing UTI, and hence to reduce inapt antimicrobial burden.
\end{abstract}

Keywords: UTI, EQUC, Uropathogens, Children, ESBL, MDR, XDR

\section{Introduction}

Urinary tract infection is one of the most common infections with a leading cause of morbidity and mortality in children [1]. However, in this age-group, the infection often remains under-diagnosed or neglected owing to nonspecific clinical presentations, patients failing to describe the actual situation, and of conventional clinical practice of diagnosis [2]. Since the 1950s, the clinical practice has relied upon SUC protocol as a gold standard in detecting etiologies contributing UTI; nevertheless, continues to be

\footnotetext{
*Correspondence: khadka.priyatam@gmail.com

†Januka Thapaliya and Priyatam Khadka contributed equally to this work

${ }^{1}$ Tri-Chandra Multiple Campus, Tribhuvan University, Ghantaghar,

Kathmandu, Nepal

Full list of author information is available at the end of the article
}

questioned for its precision in both clinical diagnosis and implicated antimicrobial therapy [3]. Hence, the precise diagnostic protocol is mandatory to reduce the superfluous antimicrobial burden and to truncate the possible adverse consequences, in the pediatric population [1-3].

Although, the documented incidence of the infection ranges from 23.1 to $37.4 \%$ in the Nepalese population [4]. In Nepal, and most developing countries, the pediatric UTIs cases are treated empirically due to lacking appropriate diagnostic protocol, unavailability of standard therapeutic guidelines, and undocumented resistivity trend of the pathogens in local and regional levels [4-6]. Therefore, a precise diagnosis of the etiologies and its resistivity status against the preferred antibiotics is crucial for successful clinical management and prophylaxis.

(c) The Author(s) 2020. This article is licensed under a Creative Commons Attribution 4.0 International License, which permits use, sharing, adaptation, distribution and reproduction in any medium or format, as long as you give appropriate credit to the original author(s) and the source, provide a link to the Creative Commons licence, and indicate if changes were made. The images or other third party material in this article are included in the article's Creative Commons licence, unless indicated otherwise in a credit line to the material. If material is not included in the article's Creative Commons licence and your intended use is not permitted by statutory regulation or exceeds the permitted use, you will need to obtain permission directly from the copyright holder. To view a copy of this licence, visit http://creativeco mmons.org/licenses/by/4.0/. The Creative Commons Public Domain Dedication waiver (http://creativecommons.org/publicdomain/ zero/1.0/) applies to the data made available in this article, unless otherwise stated in a credit line to the data. 
With these backdrops, we conducted a study to determine the etiology of UTI among children with EQUC, a slight modification on the SUC technique, to trace the significant etiologies missing on SUC.

\section{Main text}

\section{Materials and methods}

\section{Study design and sample population}

The cross-sectional study was carried out from April 2017-October 2017 in International Children Friendship Hospital, Kathmandu, Nepal. The study hospital is a tertiary referral center for children. The totals of 570 urine samples were enrolled in our study. The study populations were infants and children, not exceeding 14 years old, seeking treatment for presumed UTI.

\section{Inclusion and exclusion criteria}

Children enrolled in the pediatric outpatient department or admitted in ward, with clinical diagnosis as UTI, were included. The clinical diagnosis was made by the corresponding unit pediatrician relying upon the patient presenting with fever and/or with symptoms suggestive to UTI.

The urine samples which grew more than one type of organism were considered as a contaminant (in those children who had previously known the history of antimicrobial therapy within $48 \mathrm{~h}$ before attending the hospital) and hence, excluded from the study.

\section{Sample collection and analysis}

The urine samples (collected either with urethral catheterization, or supra-pubic aspirations and pediatric urine collection bag for toilet-untrained children, and mid-stream urine for toilet-trained children) were processed semi-quantitatively with both EQUC and SUC techniques.

In brief, the SUC protocol used $1 \mu \mathrm{l}$ of urine, spread quantitatively onto 5\% sheep blood [blood agar plate (BAP)] and MacConkey agars (BD BBL Prepared Plated Media; Hi-Media) and incubated aerobically at $35{ }^{\circ} \mathrm{C}$ for $24 \mathrm{~h}$. The urine samples were then inoculated the corresponding subset of EQUC conditions using three urine volumes $(1 \mu \mathrm{l}, 10 \mu \mathrm{l}$, and $100 \mu \mathrm{l})$ and additional plating conditions. Each urine sample was spread quantitatively onto (BAP, chocolate Agar,); chocolate agar plates were incubated in $5 \% \mathrm{CO}_{2}$ at $35^{\circ} \mathrm{C}$ for $48 \mathrm{~h}$; BAP and MacConkey agars were incubated aerobically at $35{ }^{\circ} \mathrm{C}$ for $48 \mathrm{~h}$. Only the confluent growth of a single organism, with a count of $\geq 10^{5}$ colony forming units (CFU)/ml were presumed as significant growth. For EQUC, the significant colony was calculated about volume inoculated as described by Brincat et al. with a little modification [3]. Further, microbial identification was done by using the recommended in-house set of biochemical tests and phenotypic characteristics.

\section{Antimicrobial susceptibility testing}

The antimicrobial susceptibility of bacterial isolates against different antibiotics was tested by the disk diffusion method [modified Kirby-Bauer method] on Mueller-Hinton agar (Hi-Media, India) following standard procedures recommended by the Clinical and Laboratory Standards Institute (CLSI), Wayne, PA, USA [7]. The antimicrobials used were: penicillin [ampicillin $(10 \mu \mathrm{g})$ ], penicillins with $\beta$-lactamase inhibitors [ampicillin-sulbactam $(10 / 10 \mu \mathrm{g})$, amoxicillinclavulanic acid $(10 \mu \mathrm{g})]$, narrow-spectrum cephalosporin [cefazolin $(30 \mu \mathrm{g})$ ], extended-spectrum cephalosporins [ceftazidime $(30 \mu \mathrm{g})$, ceftriaxone $(30 \mu \mathrm{g})$, cefepime $(30 \mu \mathrm{g})$ ], cephamycin [cefoxitin $(30 \mu \mathrm{g})$ ], anti-pseudomonal penicillins with $\beta$-lactamase inhibitors [piperacillin-tazobactam $(100 / 10 \mu \mathrm{g})]$, monobactam [aztreonam $(30 \mu \mathrm{g})$ ], carbapenems [imipenem $(10 \mu \mathrm{g})$, meropenem $(10 \mu \mathrm{g})$ ], aminoglycosides [gentamicin $(10 \mu \mathrm{g})$, amikacin $(30 \mu \mathrm{g})$ ], fluoroquinolones [ciprofloxacin $(5 \mu \mathrm{g})$, ofloxacin $(5 \mu \mathrm{g})$ ], folate pathway inhibitor [co-trimoxazole $(25 \mu \mathrm{g})$ ], and polymyxin [colistin $(10 \mu \mathrm{g})$ ]. The interpretations of antibiotic susceptibility results were made according to the zone size interpretative standards of CLSI [7].

\section{Identification of MDR, XDR and potential ESBL}

MDR and XDR isolates were identified about the combined guidelines of the European Centre for Disease Prevention and Control (ECDC) and the Centers for Disease Control and Prevention (CDC) [8]. The isolate resistant to at least one antimicrobial from three different groups of first-line drugs tested was regarded as MDR; while those resistant to at least one agent in all but two or fewer antimicrobial categories (i.e., bacterial isolates remains susceptible to only one or two categories) are termed as $\mathrm{XDR}[7,8]$. For the confirmation, of all potential ESBL producers, the Combined Disk test (CDT), as recommended by CLSI was performed in all isolates [7].

\section{Data management and statistical analysis}

Data obtained (patient's demographics and the results) were entered and managed on Microsoft Excel (version 2010 Microsoft Corporation, USA); the relation of variables was calculated in frequencies and percentages.

\section{Result}

\section{Patients' demographics}

Of 570 pediatric urine samples, the significant bacterial growth detected: 92 (16.14\%) with EQUC and 73 (12.8\%) with SUC protocol.

Of 92 UTI cases, the infection was higher in female children 67 (21.1\%) compared to males 25 (9.96\%). The age group, in range $1-4$ years 33 (42.9\%), and the patient admitted in wards $39(18.1 \%)$ were more prone to the infection (Table 1). 
Table 1 Patients' demographics

\begin{tabular}{llll}
\hline $\begin{array}{l}\text { Patients } \\
\text { demographics }\end{array}$ & $\begin{array}{l}\text { Uropathogen } \\
\text { detected (\%) }\end{array}$ & $\begin{array}{l}\text { Uropathogen } \\
\text { not detected (\%) }\end{array}$ & Total \\
\hline $\begin{array}{l}\text { Gender } \\
\text { Male }\end{array}$ & $25(9.96)$ & $226(90.04)$ & 251 \\
Female & $67(21.1)$ & $252(78.9)$ & 319 \\
Age group & & & \\
$<1$ year & $15(9.3)$ & $146(90.7)$ & 161 \\
1 to 4 years & $33(42.9)$ & $44(57.1)$ & 147 \\
5 to 9 years & $29(20)$ & $116(80)$ & 187 \\
10 to 14 years & $15(8.1)$ & $172(91.9)$ & 354 \\
Patients distribution & & & 216 \\
Out-patient & $53(14.98)$ & $301(85.02)$ & $177(81.9)$ \\
In-patient & $39(18.1)$ & & 145 \\
\hline
\end{tabular}

\section{EQUC vs. SUC in uropathogens detection}

EQUC detected all possible etiologies, contributing UTIs, in the clinically suspected subjects; as reported: "no growth" with the standard urine culture protocol. Of total enrolled cases, 92 significant UTIs cases were detected with EQUC; however, only 73 with SUC technique. $20.6 \%$ of isolates are being missed with the SUC technique. A statistical outline was drawn with paired t-test (Additional file 1: Table S1(a) (b)).

Among the study population, E. coli predominantly found as culprits preceding UTIs: 69 (75\%) with EQUC and 63 (68.4\%) with the SUC technique. The uropathogens i.e. Candida albicans, Provedencia retegerii, and Morganella morganii failed to grow on SUC technique; although, they grew on EQUC (Fig. 1).

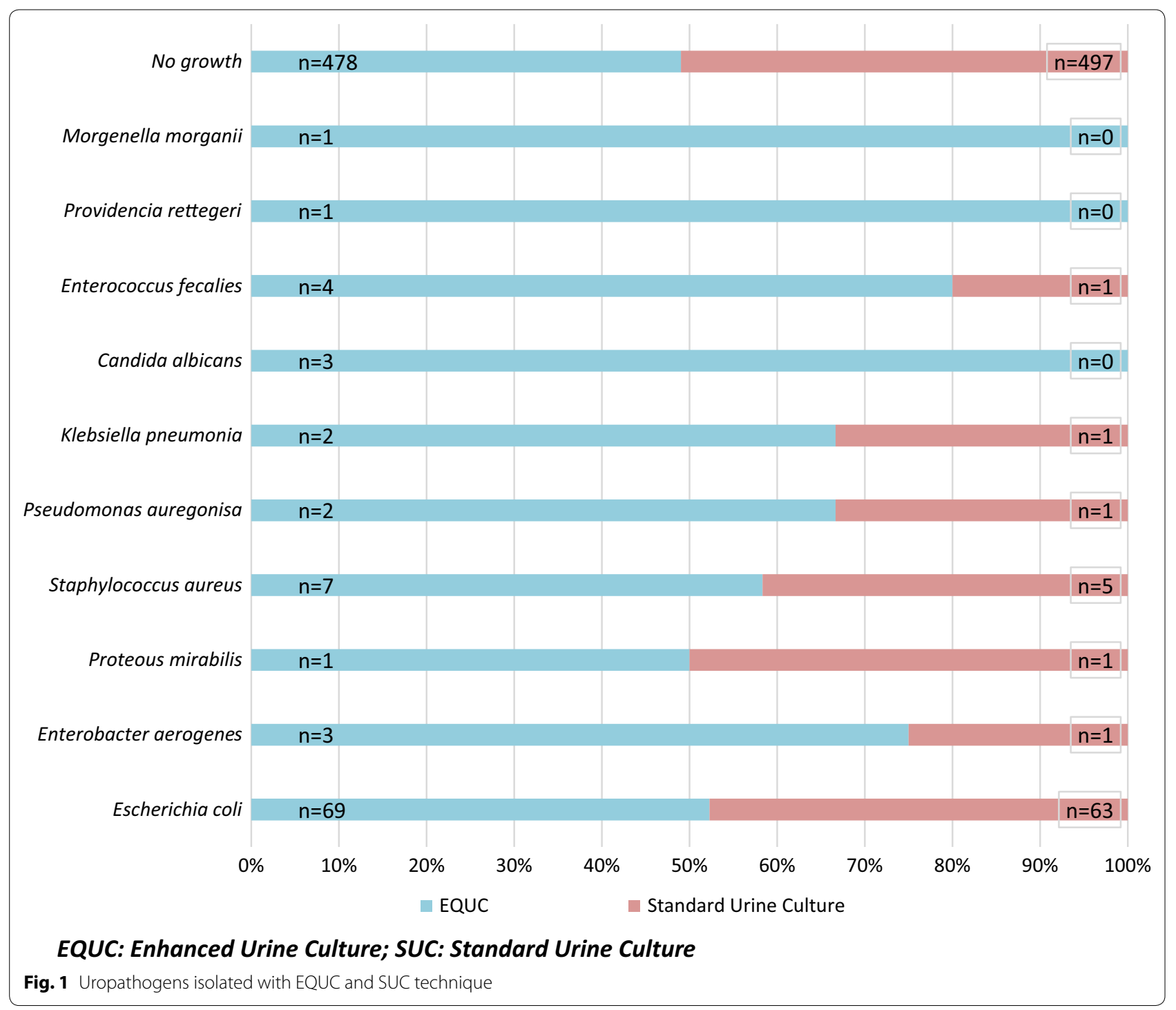


Table 2 Uropathogens detected as ESBL, MDR, and XDR with EQUC and SUC technique

\begin{tabular}{llccc}
\hline Organism isolated & $\begin{array}{l}\text { Growth } \\
\text { positivity } \\
\text { (\%) }\end{array}$ & ESBL (\%) & MDR (\%) & XDR (\%) \\
\hline EQUC & $92(16.15)$ & $32(46.0)$ & $39(56.5)$ & $1(1.4 \%)$ \\
Standard & $73(12.80)$ & $28(40.57)$ & $31(44.0)$ & 0 \\
Difference & $19(3.35)$ & $4(5.5)$ & $8(12.6)$ & $1(1.4 \%)$ \\
\hline
\end{tabular}

\section{Resistivity pattern of uropathogens}

Most E. coli isolates were resistant to ampicillin (77\%), followed by ciprofloxacin (65.07\%), cotrimoxazole (51\%), nitrofurantoin (33.3\%), gentamycin (25.3\%), cefixime (22.2\%) and ceftriaxone (22.2\%). Nevertheless, the entire strains revealed high susceptibility (up to 100\%) with colistin and tigecycline (Additional file 2: Table S2).

\section{$M D R, X D R$, and ESBL producers}

Of the total $69 \mathrm{E}$. coli isolates subjected for antimicrobial susceptibility testing: ESBL 32 (46\%); MDR 39 (56.5\%) and XDR 1 (1.4\%) detected with EQUC. The SUC protocol, however, detected ESBL 28 (40.57\%), MDR 31 (44\%) and XDR (nil) (Table 2).

\section{Discussion}

The pediatric UTI, cases are often under-diagnosed or neglected due to non-specific clinical presentations and of clinical practice-relying upon in vitro culture report; however, it may incur dire consequences. Therefore, a precise diagnosis is crucial for clinical management. In this perspective, our study underscores the insufficiencies in SUC protocol in detecting significant etiologies, possibly MDR and XDR isolates, and advocates for a slight modification concerning the sample volume being inoculated.

Among the study population, the incidence of urinary tract infection was $16.14 \%$; and E. coli $(68.5 \%)$ was the commonest pathogen. The analogous rates have been reported earlier from neighboring hospitals [4-6] and studies from other nations $[9,10]$. Alongside, significantly more females up to $72.0 \%$ had UTI substantiating with other similar studies $[5,6]$. In our study, the children of the age group 1-4 years were more prone to the infection. Our premise is comparable to findings conducted in a nearby hospital where less than 6 years were high-risk age categories $[4,6]$. The immune status, sanitation, and ascending infection with fecal flora possibly are the reasons behind such upshots in this age group.

The EQUC technique, a simple but effective technique, was embraced to determine etiologies in the clinically UTI suspected children. The same technique was applied to the women experiencing UTI like symptoms, before [3]. EQUC detected all possible etiologies, contributing UTIs as reported: "no growth" with the standard urine culture protocol. Of total 92 detected cases of UTI, 73 were isolated with SUC-conceding $20.6 \%$ being missed. However, the study population was different i.e. clinically suspected women, but similar finding favoring EQUC over SUC was attained.

Among 69 E. coli isolates, the highest resistance (77\% each) was attributed to ampicillin followed by ciprofloxacin $(65.07 \%)$. The resistance pattern was similar as observed by Parajuli et al. (87\%) to ampicillin and (78\%) to ciprofloxacin. Likewise, our findings are coherent, regarding resistance trend of the isolate against ampicillin and ciprofloxacin, to that of Ansari et al. (74\%) and (77\%); the age-group subjects was different, however [11]. The isolate, E. coli, found resistant to cefixime (22.2\%) and ceftriaxone (22.2\%). Among antimicrobials tested, colistin (100\%), imipenem (nearly 99\%) were sensitive. Therefore, a second and third-generation cephalosporin (cefixime and ceftriaxone) could be choices; polymyxin (colistin) and carbapenem (imipenem) could better be opted-in treating childhood UTI.

The etiology, Staphylococcus aureus, in pediatric UTI is commonly associated with acquired infection preceding from in-dwelling catheters or other devices [12]. Of 7 isolates of Staphylococcus aureus, 5 were recovered from the patient after catheterization; 2 of the isolates were resistant to ampicillin and cotrimoxazole; while one each found resistant to ofloxacin, cloxacilline, cefoxitine, cephalexine, and nitrofurantoin. The single isolate was methicillin-resistant Staphylococcus aureus (MRSA); as reported by some authors in the pediatric population [13, 14].

The uropathogens (Candida albicans, Provedencia retegerii, and Morganella morganii) were isolated with EQUC while missed on SUC; although, these pathogens were cited, as the significant etiologies contributing childhood UTI [15-18]. Hence from our study, it can be clinched that each uropathogens, possibly significant causative agent, may have its' own unique threshold bacterial load, concerning the volume to be inoculated on culture media.

Apart from these, our study underscores 5.5\% of ESBL, $12.6 \% \mathrm{MDR}$, and $1.4 \%$ of XDR isolates were about to be missed if only SUC has opted. In this study, MDR and XDR isolates were found $56.5 \%$ and $1.4 \%$ respectively while $46 \%$ of uropathogens were found ESBL producers. Nevertheless, an increasing pattern of resistance trend in uropathogens, along with MDR rates has been reported, among pediatric isolates, from Nepal $[5,6,19]$. The level of drug-resistant uropathogens among the children in this study is of serious concern; nevertheless, the exact 
figures with exact anti-microbial resistance status (that possibly missed on SUC) were not analyzed before.

In most developing countries like Nepal, the higher antimicrobial burden preceding inapt therapeutic guidelines among pediatric patients might be attributable to the intimidating scenario [4-6]. Existing higher rates of ESBL, MDR, and XDR; necessitates the use of carbapenem, colistin, tigecycline, and other mono-antimicrobial therapies (cephamycins, fosfomycin and nitrofurantoin); however, the resistance to these potent therapeutic options may not be stood robust till longer due to emerging MDR strains [11, 20-23].

\section{Conclusion}

EQUC detects uropathogens, possibly MDR, XDR, and ESBL producers, which could be reported: "no growth" on the SUC protocol. Therefore, a simple modification, on conventional culture protocol could be a crucial modification for the detection of etiologies, and to reduce inapt antimicrobial burden.

\section{Limitation of the study}

We could not encompass the large sample size with this new modification-the EQUC technique. Our study was restricted to phenotypic anti-microbial resistance detection excluding the identification of different beta-lactamases producing isolates. Although, genomic sequencing provides insightful resistance trend due to constricted laboratory resources was not included in our study.

\section{Supplementary information}

Supplementary information accompanies this paper at https://doi. org/10.1186/s13104-019-4875-y.

Additional file 1: Table S1. (a) Paired sample t-test EQUC and SUC technique. (b) Paired differences.

Additional file 2: Table S2. Resistivity pattern of uropathogens.

\section{Abbreviations}

ASM: American Society for Microbiology; ATCC: American Type Culture Collection; CLSI: Clinical and Laboratory Standard Institute; E. coli: Escherichia coli; EQUC: enhanced quantitative urine culture; ESBL: extended-spectrum beta-lactamase; MDR: multiple drug-resistant; SUC: standard urine culture; UTI: urinary tract infection; XDR: extensive drug-resistant.

\section{Acknowledgements}

We are profoundly obliged to all the patients participating in this study. Our special thanks go to all the laboratory staff, management and officials of International Friendship Children's Hospital Kathmandu for providing the opportunity to carry out this research work.

\section{Authors' contributions}

PK and JT made the diagnosis, designed the manuscript, reviewed the literature and prepared the article for submission. ST and CG helped for literature reviews gave a concept of research paper and critically reviewed the manuscript. All authors read and approved the final manuscript.

Funding

Not applicable.

\section{Availability of data and materials}

Data generated or analyzed during this study are included in this published article and remaining are available from the corresponding author on reasonable request.

\section{Ethics approval and consent to participate}

This research was approved by the Institutional Review Committee of International Friendship Children's Hospital, Kathmandu, Nepal. Written informed consent was taken from the patients or their parents before participating in the study. Data regarding personal information and infectious disease were coded and kept confidential.

\section{Consent for publication}

Not applicable.

\section{Competing interests}

The authors declare that they have no competing interests.

\section{Author details}

${ }^{1}$ Tri-Chandra Multiple Campus, Tribhuvan University, Ghantaghar, Kathmandu, Nepal. ${ }^{2}$ International Friendship Children's Hospital, Kathmandu, Nepal.

Received: 17 Auqust 2019 Accepted: 24 December 2019

Published online: 03 January 2020

\section{References}

1. Zorc JJ, Kiddoo DA, Shaw KN. Diagnosis and management of pediatric urinary tract infections. Clin Microbiol Rev. 2005;18(2):417-22. https://doi. org/10.1128/CMR.18.2.417-422.2005.

2. Quigley R. Diagnosis of urinary tract infections in children. Curr Opin Paediatr. 2009;21(October):194-8.

3. Price TK, Dune T, Hilt EE, Thomas-White KJ, Kliethermes S, Brincat C, et al. The clinical urine culture: enhanced techniques improve detection of clinically relevant microorganisms. J Clin Microbiol. 2016;54(5):1216-22.

4. Rai GK, Upreti HC, Rai SK, Shah KP, Shrestha RM. Causative agents of urinary tract infections in children and their antibiotic sensitivity pattern: a hospital based study. Nepal Med Coll J. 2008;10(2):86-90.

5. Singh SD, Madhup SK. Clinical profile and antibiotics sensitivity in childhood urinary tract infection at Dhulikhel Hospital. Kathmandu Univ Med J (KUMJ). 2013;11(44):319-24.

6. Parajuli NP, Maharjan P, Parajuli H, Joshi G, Paudel D, Sayami S, et al. High rates of multidrug resistance among uropathogenic Escherichia coli in children and analyses of ESBL producers from Nepal. Antimicrob Resist Infect Control. 2017;6(1):1-7. https://doi.org/10.1186/s13756-016-0168-6.

7. CLSI. Performance standards for antimicrobial susceptibility testing. CLSI supplement M100. 27th ed. Wyne: Clinical and Laboratory Standard Institute; 2017.

8. Magiorakos A, Srinivasan A, Carey RB, Carmeli Y, Falagas ME, Giske CG, et al. Bacteria: an International Expert proposal for interim standard definitions for acquired resistance. Microbiology. 2011;18(3):268-81. https ://doi.org/10.1111/j.1469-0691.2011.03570.x/full.

9. Flokas ME, Detsis M, Alevizakos M, Mylonakis E. Prevalence of ESBLproducing Enterobacteriaceae in paediatric urinary tract infections: a systematic review and meta-analysis. J Infect. 2016;73(6):547-57.

10. Moore CE, Sona S, Poda S, et al. Antimicrobial susceptibility of uropathogens isolated from Cambodian children. Paediatr Int Child Health. 2016;36(2):113-7. https://doi.org/10.1179/2046905515Y.0000000008.

11. Ansari S, Nepal HP, Gautam R, Shrestha S, Neopane P, Gurung G, et al. Community acquired multi-drug resistant clinical isolates of Escherichia coli in a tertiary care center of Nepal. Antimicrob Resist Infect Control. 2015;4:15. 
12. Schlager TA. Urinary tract infections in children younger than 5 years of age: epidemiology, diagnosis, treatment, outcomes and prevention. Paediatr Drugs. 2001;3(3):219-27.

13. Muder RR, Brennen C, Rihs JD, Wagener MM, Obman A, Obman A, et al. Isolation of Staphylococcus aureus from the urinary tract: association of isolation with symptomatic urinary tract infection and subsequent Staphylococcal Bacteremia. Clin Infect Dis. 2006;42(1):46-50. https://doi. org/10.1086/498518.

14. Gupta P, Mandal J, Krishnamurthy S, Barathi D, Pandit N. Profile of urinary tract infections in paediatric patients. Indian J Med Res. 2015;141:473-7.

15. Wie S-H. Clinical significance of Providencia bacteremia or bacteriuria. Korean J Intern Med. 2015:30:167-9.

16. Acar JF, Goldstein FW. Trends in bacterial resistance to fluoroquinolones. Clin Infect Dis. 1997;24(Suppl 1):S67-73.

17. Fisher JF, Sobel JD, Kauffman CA, Newman CA. Candida urinary tract infections-treatment. Clin Infect Dis. 2011;52(Suppl 6):S457-66.

18. Bitsori M, Maraki S, Koukouraki S, Galanakis E. Pseudomonas aeruginosa urinary tract infection in children: risk factors and outcomes. J Urol. 2012;187(1):260-4. https://doi.org/10.1016/j.juro.2011.09.035.

19. Sharma A, Shrestha S, Upadhyay S, Rijal P. Clinical and bacteriological profile of urinary tract infection in children at Nepal Medical College Teaching Hospital. Nepal Med Coll J. 2011;13(1):24-6.
20. Bryce A, Hay AD, Lane IF, Thornton HV, Wootton M, Costelloe C. Global prevalence of antibiotic resistance in paediatric urinary tract infections caused by Escherichia coli and association with routine use of antibiotics in primary care: systematic review and meta-analysis. BMJ. 2016;352:1939.

21. Dalgic N, Sancar M, Bayraktar B, Dincer E, Pelit S. Ertapenem for the treatment of urinary tract infections caused by extended-spectrum beta-lactamase-producing bacteria in children. Scand J Infect Dis. 2011;43(5):339-43.

22. Park SH, Choi S-M, Chang YK, Lee D-G, Cho S-Y, Lee H-J, et al. The efficacy of non-carbapenem antibiotics for the treatment of community-onset acute pyelonephritis due to extended-spectrum beta-lactamase-producing Escherichia coli . J Antimicrob Chemother. 2014;69(10):2848-56.

23. Asakura T, Ikeda M, Nakamura A, Kodera S. Efficacy of empirical therapy with non-carbapenems for urinary tract infections with extendedspectrum beta-lactamase-producing Enterobacteriaceae. Int J Infect Dis. 2014:29:91-5.

\section{Publisher's Note}

Springer Nature remains neutral with regard to jurisdictional claims in published maps and institutional affiliations.
Ready to submit your research? Choose BMC and benefit from:

- fast, convenient online submission

- thorough peer review by experienced researchers in your field

- rapid publication on acceptance

- support for research data, including large and complex data types

- gold Open Access which fosters wider collaboration and increased citations

- maximum visibility for your research: over $100 \mathrm{M}$ website views per year

At BMC, research is always in progress.

Learn more biomedcentral.com/submissions 